\title{
A conceptualisation of the post-museum as pedagogical space
}

\author{
Richard Watermeyer
}

\begin{abstract}
This paper explores the idea of the post-museum as an immersive knowledge experience facilitating conceptual and strategic directions in public engagement with science and technology. It considers the extent to which the museum has evolved from repository of cultural artefacts to experience-based process of knowledge acquisition and production. The post-museum is invoked as a model of participatory pedagogy that moves beyond traditional forms of learning, knowledge acquisition and knowledge interface, and conceptualisations of the learner in science. It is presented as an educational and recreational experience, which locates and translates knowledge to the novice or non-traditional patron using rich social narratives that ground scientific expertise in the practice of everyday life. The experience of science is thus made familiar and relevant and concurrently regulated and owned by the visitor. The learner is consequently recast from passive recipient of information-bites to choreographer, translator and innovator within a scientific knowledge continuum.
\end{abstract}

\section{Preamble}

The following discussion takes its cue from an interest in how the social and material architecture of public spaces is co-opted for the democratisation and/or 'making public' of expert knowledge. It forms part of a programme of research focused on how public spaces, specifically public spaces of learning or spaces of public learning, expedite the translation and transfer of complex knowledge in ways, which invoke the public's scientific imagination and catalyse the 'citizen-scientist'. 1,2

The account that follows offers a conceptualisation of the museum not as an edifice but experience of science - a post-museum or what Bourriard ${ }^{3}$ calls a 'relational aesthetic', which rehabilitates and renews the interface between science and its lay communities; propagates the public's fascination with science and/or the public's scientific imagination and scaffolds a potentially lifelong learning journey; and reconfigures the museum as a public and pedagogical space. The museological lens is consequently adopted to further interrogate, problematize and ameliorate conceptual and strategic directions in public engagement with science.

\section{Introduction}

In recent years, substantial funding of the museum sector has facilitated methodological innovations informing how expert knowledge is communicated and made available to the public in explicitly participatory ways. ${ }^{4}$ In tandem, this has generated an increased recognition of the value of informal learning among all age cohorts $;^{5}$ new interest in technologically facilitated communication; ${ }^{6}$ 'interactivity' or interpersonal communication; ${ }^{7}$ and the continuation of a sociological tradition in the communication of scientific complexity to lay audiences. ${ }^{8}$ This has occurred in the West with the emergence of a learning society and a shift from industrial to knowledge based or information economies; the massification of education; and new technologically assisted platforms for knowledge generation, dissemination and sharing.

Strategic reorientations in learning design and praxis have underpinned this transition. A need for new learning paradigms in negotiation of knowledge, ubiquitously, instantly and continuously cascading via digital and mobile fora, analogous to what Shenk ${ }^{9}$ describes as an information saturated society; a move 
towards constructivist, personalised approaches to learning; ${ }^{10}$ a growing recognition of the benefits of non-school sources of education; ${ }^{11}$ and notions of learning as leisure or what Falk et al. ${ }^{12}$ call 'free choice learning' have altered conceptualisations of the learner and approaches to learning, from the perspective of both educational providers and learners themselves.

Though not originally nor always latterly intended as an educational space, ${ }^{13}$ the museum has in parts evolved as a site for highly individualised and immersive forms of science learning. Indeed, as Marstine ${ }^{14}$ suggests, learning is increasingly an integral component of museum practice. A contemporary focus for museum learning is in then prioritising the uniqueness of each visitor and their varying if disparate learning experiences and learning outcomes - adopting a constructivist learning approach. ${ }^{15,16}$

This paper provides a theoretical discussion of the way with which new interactive museums or what Hooper-Greenhill ${ }^{17}$ describes as 'post-museums', organise and reconceptualise space for the emancipation of the visitor from proscriptive curatorial and learning styles and agendas, accordingly opening and expanding new spaces for public participation in science. The post-museum is considered for its potential to recruit, support and sustain non-traditional audiences through a model of experiential learning ${ }^{18,19}$ and as one iteration of the public sphere ${ }^{20}$ that culminates with a scientifically engaged public.

\section{Postmodernism and the Interactive Turn}

Interactive-focused museums and science centres, which use immersive-simulated environments and multimedia/sensory/touch-feel-experience displays are celebrated for their ability to engage with the socio-cultural and physical contexts of visiting and the diverse cognitive frameworks of visitors that differentiate learning styles. 'Interactives ${ }^{, 21}$ are credited, by virtue of being 'hands-on', as pedagogically superior to traditional museum formats ${ }^{22,23,24}$ allowing visitors to experiment and play with exhibits and generate their own frames of reference and meaning. They are championed by their advocates, as circumventing the didactic or prescriptive characteristics of conventional forms of transmission pedagogy; which visitors find off-putting or outmoded. ${ }^{25}$ Indeed, Macdonald ${ }^{26}$ comments on how museum staff routinely refer to interactives as democratising tools empowering visitors as active decision-makers. There is however a corpus of dissent that argues against the effectiveness of interactives. ${ }^{27,28}$ Critics such as George Hein ${ }^{29}$ argue that a 'minds-on' formula is a more efficacious and democratic approach to learning than 'hands-on' pedagogy. Others comment that interactives distract from analytical and critical readings ${ }^{30}$ and fail to connect with larger debates in society. ${ }^{31}$

In a purported milieu of 'hyper-reality', 32 'consumer culture, ${ }^{33}$ and 'culture as showbusiness', 34 detractors of the interactive approach argue that the museum has been relegated to a 'supermarket of culture'. ${ }^{35,36}$ Virilio $^{37}$ for instance argues that the rampant ascent of visual and audiovisual technologies has ravaged mnemonic recall and retention and instated an 'automation of perception' or what Baudrillard $^{38}$ refers to as 'yes or no' responses among museum visitors. Others bemoan the sensory overload of an 'information society' ${ }^{39}$ and the demise of contemplation, which in the museum context is subjugated by a commercialist edict of instant gratification and the infantilisation, if dénouement, of the spectator as aesthetic journeyman. The museum experience it follows becomes a fractured and inchoate repertoire of mini-epics and entertainment detours which enervate the capacity of the visitor to accrue deeper, more nuanced and complete observations and associations. The museum narrative is in this context obscured and atomized. Far from a lucid and intelligible interface with new knowledge the museum visit is confounded by a tendency to induce a disparate jumble of impulsive behaviours or what Jameson $^{40}$ calls a 'phenomenology of mixed reactions', which cause the homogenization and stasis of its public experience and inefficacy as a catalyst inspiring knowledge and learning.

Through the postmodern lens the commodification of knowledge has profoundly altered the ways with which science is experienced and rationalised. Lyotard ${ }^{41}$ argues that,

Knowledge is and will be produced in order to be sold, it is and will be consumed in order to be valorized in a new production.

The museum experience is from this perspective not focused on learning and pedagogy but its status as a commodity of the knowledge economy where the experience of knowledge, or be that quasiknowledge, is the new recreation. In response to the pressures of a consumer society, museums have reconfigured themselves as 'distraction machines', ${ }^{42,43}$ vying for patronage in an increasingly competitive 
and saturated market. The post-museum in this context is positioned as both a 'place of learning and knowledge and a place of enjoyment'. ${ }^{44}$ Balancing these priorities is however complicated by forces of marketization and a need for museums to compete with other family focused attractions with bigger budgets and better resourced marketing strategy. ${ }^{45}$ The intercession and prioritisation of commercial interests in the governance of the museum has caused, for some purists, the desertion of its founding principles. Furthermore, the museum's commitment to fulfilling the expectations and standards of a recreational economy, principally through the indiscriminate investment and use of technologically facilitated mediation, is seen to have ironically culminated with the disenchantment, fatigue and ennui of the museum patron. ${ }^{46}$ The Disneyfication of the museum sector and a modern accent on theme-park thrills are seen to further debilitate the contemplative mood and the potential for museum visitors to engage with individual exhibits in any meaningful way. ${ }^{47}$ Bauman $^{48}$ refers to this as,

$$
\begin{aligned}
& \text {... the peculiar fashion in which the members of a society of consumers think of behaving or in } \\
& \text { which they behave 'unreflexively' ... }
\end{aligned}
$$

Notwithstanding, consideration of the museum as post-museum and site of experiential and informal learning is not as many postmodern critics surmise, redundant, but in need as Prior ${ }^{49,50}$ proposes of closer inspection. Indeed, where some critics correlate changes to the museum with the erosion of its aesthetic or museological denouement, others consider its contemporization as producing a 'complex, doubleended organization in which composite tendencies are absorbed and played out'. 51

\section{The Post-Museum}

Postmodernists argue that the museum, encountered simply and purely as a building, has evolved and been seceded by the era of the post-museum, imagined as a knowledge process or experience. ${ }^{52}$ In this way of thinking, the museum has evolved from a repository of material culture that articulates personal and national identity ${ }^{53}$ to a process of cultural exchange that perpetuates community dialogue and ongoing constructions of meaning. ${ }^{54}$ The museum has as Auge ${ }^{55}$ might suggest, become a 'non-place' an unstable, eclectic ensemble of aesthetic or cultural narratives.

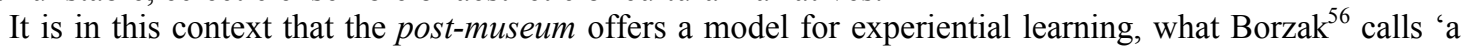
direct encounter with the phenomena rather than merely thinking about the encounter' and a unique platform for public engagement with science and technology. Its modus operandi privileges social interaction and lived experience as a means to invoke and elucidate scientific discourse. In a Goffmanesque $^{57}$ sense, the post-museum is the enactment or performance of scientific knowledge, made apparent and available through a process of creative and participatory visualization. At its paradigmatic heart the post-museum mobilizes the visualization of science through the human-self, or the story of science as told through the intersecting strands of social and cultural narrative. The post-museum is a process of investing science with its social and cultural heritage and imagining its cultural legacy. It is an interface that connects the life of the non-expert with the life of the expert and clears a way for 'dialogue'. ${ }^{58}$ It is a process of humanizing science or making science known through the project of being human.

Transformed from isolated and passive to collective and participatory the post-museum experience is primed not only to enlarge the critical consciousness and sharpen the critical lens but extend the diversity of its patrons. The post-museum is for and belongs to educators, museum specialists, scientists, students, artists, parents, the general populace. It is, as an experience or interface with science, not confined to one destination. It is not only the San Francisco Exploratorium or London Science Museum. It is also a webcast, a podcast, a blog, a Facebook posting, or online game. It is any means of expressing science where science is the manifestation of human interaction and endeavour. The post-museum represents therefore the performance or embodiment of a community in the process of assimilating, contesting and/or synthesising scientific knowledge and mechanism which engenders the socially conscious and democratically mobile citizen. ${ }^{59,60,61}$ It is in this context that some educational theorists like Usher et al. ${ }^{62}$ signpost the museum as a unique space facilitating the emergence of identity, which Weedon ${ }^{63}$ argues propels the knowing subject - the active, self-determining, efficacious student of science. However the post-museum as a site of bricolage and multiple epistemic assemblages calls into question what the knowing subject takes as known. 
In what Bauman ${ }^{64}$ refers to as an age of 'liquid modernity' or Augé ${ }^{65}$ calls 'supermodernity', the postmuseum is poised as a space that reflects and responds to uncertainty and contingency - it is a 'symbolic place of difference and divergence'. ${ }^{66}$ Simultaneously, it fulfils changing expectations of the learning contract, which Hooper-Greenhill ${ }^{67}$ depicts as 'foregrounding play and desire, rather than a search for a proscribed pre-determined end'. Bennett ${ }^{68}$ claims that creative exhibition curatorship, evidenced within the interactive turn, mobilises the ambiguity of objects and the unpredictability of visitors' engagement with them to diversify knowledge. In this way the architecture of knowledge constantly shifts, invoking multiple permutations of scientific understanding. There is however a danger with this that where public understandings of science become so multifarious and diffuse popular misinformation breeds. Macdonald ${ }^{69}$ refers to this as the 'pubic understanding of science paradox'.

A post-museum focus on participatory experience is intended to empower the visitor by building confidence and tapping wells of creativity and self-expression that generate moments of selfactualization. $^{70}$ With participative exploration comes personal constructionism ${ }^{71}$ which liberates the museum from the staidness of ritualistic convention by privileging the meditations of new users/customers/collaborators of scientific knowledge. Through the post-museum, meaning making thus mutates from uni-directional, undiscriminating, detached and one-dimensional into an immersive, multiple, collaborative event that exhibits many voices and perspectives:

Knowledge is no longer unified and monolithic; it becomes fragmented and multi-vocal. There is no necessary unified perspective - rather a cacophony of voices may be heard that present a range of views, experiences and values. The voice of the museum is one among many. ${ }^{72}$

It is in this context that the post-museum represents fertile ground for public dialogue, the 'upstreaming' of public involvement in matters of scientific and technological complexity, ${ }^{73,74}$ and the cultivation of what Jasanoff ${ }^{75}$ calls 'civic epistemologies'. The unfolding of scientific technocracy accordingly begins with a perceptual reorientation from the scientific to the social or the scientific through the social.

The post-museum presents a gateway to a myriad of social narratives. Its collection may disseminate not single but multiple histories; stories told through 'subtle juxtapositions of experience' ${ }^{76}$ As a sensorial immersive experience the post-museum may concurrently facilitate new knowledge; 'a result of a creative process based on imagination'. ${ }^{77}$ Creative learning may further intellectual curiosity, autonomy, flexibility and risk taking, whilst consolidating learner motivation and engagement. ${ }^{78}$ Simultaneously, object-based learning may facilitate the development of the imagination; ${ }^{79}$ instil a greater motivation to learn; ${ }^{80}$ and make available learning pathways where thoughts, knowledge and emotions are articulated without need of words. ${ }^{81,82}$

The post-museum thus emerges from the certainty of its predecessor as a series of signposts declaring a route, albeit mazy, risk-laden and perhaps as one of many, that leads to knowledge. As one knowledge pathway, the post-museum is suggestive and formative and though in some way authoritative, inconclusive and iterative. More than just containing and displaying scientific artefacts the post-museum provides a compass for the knowledge orienteer to navigate an experience of them; proferring an individualised or personalised level of engagement. It is first and foremost an emergent space; designed and built by the interpretations and projections of critical agency that foment contestation and the 'negotiation of hegemony', 83 absolutes or incontestable conclusions made of and by science. The postmuseum is as such a birth-pool and proscenium for an inquiring public and the materialization of a public discourse in science.

\section{The Post-Museum as a Public Sphere}

Ashley ${ }^{84}$ argues that whilst the museum can be seen to represent or reinforce the hegemonic agency of state $^{85}$ it concurrently and paradoxically exists as a public sphere for the discussion, disputation and (re)generation of scientific knowledge. It is a public forum, theoretically open to all and where large assemblies may coalesce to participate in a myriad of events, programmes and lectures. The museum concurrently challenges the authority of the scientific expert in so much as museum professionals are redefined as Bauman ${ }^{86}$ argues from 'legislators' to 'interpreters' of knowledge. In this way the museum fulfils Habermas ${ }^{87}$ ideal of the public sphere as an equitable space for the rational determination of the 'public good'. Indeed, beyond the exhibition, the museum contributes to a series of events, where the 
multiple aspects of science as culture are democratised, enriched and mobilised. These comprise community and organisational partnerships; educational programmes; and temporary residencies by specific groups such as writers, scientists and artists-in-residence who re-designate the parameters and function of museum space to suit their own needs. The elasticity or tractability of museological practice/experience in this context is what transforms the museum into a viable space for public/expert integration and collaboration in science and its fulfilment as the post-museum, which as an experiential gateway abandons 'the values of objectivity, rationality, order and distance' to 'negotiate responsiveness, encourage mutually nurturing partnerships and celebrate diversity'. ${ }^{88}$

The post-museum as a component of the public sphere thus corresponds to what Taylor ${ }^{89}$ depicts as the 'social imaginary' - citizens voicing opinions in a public space that exists beyond state power. As a lever from official forms of wisdom, the post-museum represents a genuinely critical and democratic space intended for experiential learning and dialogic participation in science. It subverts knowledge hierarchy, certitude and absolutism with a deliberate looseness and playful exuberance that stimulates the visitor to contest received wisdom and confidently and legitimately participate in new epistemologies. ${ }^{90}$ As distinct from the national museum, which has historically corroborated with the grand and oppressive narrative of Eurocentric modernity, the post-museum offers a liminal space or threshold for scientific (re)interpretation, where social agents collectively dissent and resist imposed and normative discourses. ${ }^{91}$ The post-museum is then one expression of the public voice as an able, integral and stabilising contributor in the production of scientific discourse. ${ }^{92,93}$

Where the objective of the traditional museum was to provide specific, non-arbitrary meanings via the display of cultural objects, the post-museum confuses and complicates. It occurs as a zone of 'liminality' 94 and of abstraction leading to unanticipated possibilities for engagement with scientific complexity. The transitory nature of its experience, as a brief, arguably unsustainable interlude or stimulus to meaning making, is also however important. The museum visit is almost a period of 'realtime' stasis, a point of interruption, which allows what Bazin ${ }^{95}$ calls 'momentary ephiphanies' that induce from the spectator 'the illusion of knowing intuitively his essence and his strengths'. These moments of insight correspond to what Hooper-Greenhill ${ }^{96}$ refers to as 'learning at a glance' a type of incidental, latent or serendipitous learning where the exposition of scientific knowledge occurs as a punctuation or interstice to daily life and as an evocative snap-shot triggering prolonged reflection. The suspension of temporality in this case provides a buffer, an intermission from daily convention and an opportunity to deliberate, introspect and meaning make. With this momentary hiatus, the spectator may escape the constraints of mundane or superficial experience and as Pearce ${ }^{97}$ suggests, entertain larger, more fulfilling and meaning-rich perspectives.

The extent by which the museum has become a living laboratory, worthy of emulation in other knowledge institutions, directly corresponds to the success of its reinvention as a participative learning zone and immersive social space; and its own cultural and organisational renaissance from mausoleum of cultural relics and antiquities to experiment of social/scientific living. The learning potential of the museum is as an experience, which revivifies forgotten or dulled emotions that reconnect a sense of place in the world, and by extension embeds a capacity to manage and sustain this relationship.

Contemporary museums are however not only equipped with the potential 'to be ideal learning environments across the age-range ${ }^{98}$ but exist as indispensable communicative channels, which Weil ${ }^{99}$ argues:

...will make available to the community, and for the community's purposes, its profound expertise at telling stories, eliciting emotion, triggering memories, stirring imagination, and prompting discovery.

\section{Conclusion}

The proposal of the post-museum as a 'New Institution' ${ }^{100}$ represents an epistemological turning-point and operational realignment of the museum from a bank to a broker or intermediary of scientific knowledge, empowering visitors as architects and regulators, authors and owners of an increasingly personalized museum experience and individualized account of science. Through an investment in the personalization, localization and creative visualization of science and technology the post-museum represents a new addition to the conceptual repertoire of public engagement with science and technology; 
which appears decidedly 'upstream' in nature, incorporating non-expert groups in the early stages of scientific inquiry Indeed, the post-museum is indicative not only of a contemporary trend for knowledge exchange and transfer between expert and non-expert communities that typifies the broader role of science communication as a means of democratisation and social egalitarianism, but signposts a reconfiguration in the processes and conventions of knowledge production itself, and that an investment in the public as co-author and co-investor in scientific discourse is not negligent, profligate or misplaced but predicated on an understanding of the public as a competent and able collaborator and handler of scientific knowledge. The post-museum is thus a promissory yet no less plausible proposition, premised on the manifestation of science in the public imagination not as a narrative told but a narrative in the making.

Finally, through an emphasis on playful and creative experiences, the post-museum provides a pedagogical alternative which may help to instil a greater awareness, enthusiasm and empathy for science among learners of all ages and all types; and without the fear expressed by some that the amplification of enjoyment and fun is to the detriment of the learning experience, contemplative mood or aesthetic value of the museum. Re-imagined as an experience less edifice of science, the museum as post-museum makes plain the educational value permeating recreational and entertaining forms of cultural activity and that as Kalliala ${ }^{101}$ argues play itself 'paves the way for learning'. The post-museum ostensibly is thus one route not only to greater participation and inclusion in science but the elucidation of multiple publics in science.

\section{Notes and references}

1 R. Bonney and M. LaBranche (2004), Citizen Science: Involving the Public in Research, ASTC Dimensions, 13.

2 D. Brossard, B. Lewenstein and R. Bonney (2005), Scientific Knowledge and Attitude Change: The Impact of a Citizen Science Project, International Journal of Science Education 27(9): 1099-1121.

3 N. Bourriard (2002), Relational Aesthetics, Dijon: les presses du reel.

4 C. Heath and D. vom Lehn (2008), Configuring “Interactivity": Enhancing Engagement in Science Centres and Museums, Social Studies of Science 38(1), 63-91

5 H.S. Hein (2000), The Museum in Transition: A Philosophical Perspective, Washington DC \& London: Smithsonian Institution Press.

6 J.M. Bradburne (2000), Interaction in Museums: Observing Supporting Learning, Libri Books on Demand, Hamburg.

7 C. Scott (Ed.) (2004), Interactivity, Curator (Special Edition) 47(2).

${ }^{3}$ S. Yearley (2004), Making Sense of Science. Understanding the Social Study of Science, Sage, London.

9 D. Shenk (1997), Data smog: Surviving the Information Glut, Abacus, London.

${ }^{10}$ G.E. Hein (2011), Museum Education, in S. Macdonald (Ed.), A Companion to Museum Studies, Wiley-Blackwell, Chichester.

${ }^{11}$ W.J. Hilton (1981), Lifelong learning, in K . Cirincione-Coles (ed.), The Future of Education: Policy Issues and Challenges, pp. 147-57, Sage, Beverly HIlls, CA.

12 J.H. Falk and L.D. Dierking (2000), Learning from Museums: Visitor Experiences and the Making of Meaning, New York and Oxford, Alta Mira.

${ }^{13}$ Falk et al. (2000).

${ }^{14}$ J. Marstine (Ed.) (2006), New Museum Theory and Practice: An Introduction, Oxford: Blackwell.

${ }^{15}$ J. Rounds (Ed.) (1999), Special Issue on Meaning Making, Exhibitionist 18(2): 5-44.

${ }^{16}$ L.H. Silverman (1995), Visitor Meaning-making in Museums for a New Age, Curator 38(3): 161-170.

${ }^{17}$ E. Hooper-Greenhill (2000), Museums and the Interpretation of Visual Culture, Routledge, London.

${ }^{18}$ D.A. Kolb (1984), Experiential Learning: Experience as the Source of Learning and Development, Prentice-Hall, Englewood Cliffs, NJ.

${ }^{19}$ J. Dewey (1938), Experience and Education, Collier Books, New York.

${ }^{20}$ J. Habermas (1989), The Structural Transformation of the Public Sphere, Polity, Cambridge.

${ }^{21}$ A. Witcomb (2011), Interactivity: Thinking Beyond, in S. Macdonald (Ed.), A Companion to Museum Studies, Wiley-Blackwell Chichester.

${ }^{22}$ K. McLean (1993), Planning for People in Museum Exhibitions, Association of Science-Technology Centers, Washington DC.

${ }^{23}$ T. Russell (1994), The Enquiring Visitor: Usable Learning Theory for Museum Contexts, Journal of Education in Museums 15: 19-21.

${ }^{24}$ J. Stevenson (1994), Getting to Grips, Museum Journal 94(5): 30-32.

${ }^{25}$ G.F. MacDonald (1992), Change and Challenge: Museums in the Information Society, in I. Karp, C. Mullen Kreamer and S.D. Levine (Eds.), Museums and Communities: The Politics of Public Culture, Smithsonian Institution Press, Washington DC.

${ }^{26}$ S. Macdonald (2002), Behind the Scenes at the Science Museum, Berg Oxford.

${ }^{27}$ M. Borun, C. Massey and T. Lutter (1993), Nä̈ve Knowledge and the Design of Science Museum Exhibits, Curator 36(3): 201219.

${ }^{28}$ McClafferty (1995), Did You Hear Grandad? Children's and Adults' Use and Understanding of a Sound Exhibit in an Interactive Science Centre, Journal of Education in Museums 16: 12-16.

${ }^{29}$ G.E. Hein (1998), Learning in the Museum, Routledge, London. 
${ }^{30}$ B. Reid and V. Cave (1995), The All Hands Interactive Gallery at the National Maritime Museum, Journal of Education in Museums 16: 27-8.

${ }^{31}$ A. Barry (1998), On Interactivity: Consumers, Citizens and Culture, in S. Macdonald (Ed.), The Politics of Display: Museums, Science, Culture, Routledge, London.

32 J. Baudrillard (1998), The Consumer Society: Myths and Structures, Sage, London.

${ }^{33}$ Z. Bauman (2007), Consuming Life, Polity Press, Cambridge.

${ }^{34}$ U. Eco (1987), Travels in Hyperreality, Picador, London.

${ }^{35}$ P. Virilio (1991), The Aesthetics of Disappearance, Semiotext, Paris.

${ }^{36}$ M. Featherstone (1991), Postmodernism and Consumer Culture, Sage, London.

${ }^{37}$ P. Virilio (1994), The Vision Machine, British Film Institute, London.

${ }^{38}$ J. Baudrillard (1994), Simulacra and Simulation, University of Michigan Press, MI.

${ }^{39}$ M. Castells (2000), The Rise of the Network Society, The Information Age: Economy, Society and Culture: Volume 1. Malden: Blackwell (2nd Ed.).

${ }^{40}$ F. Jameson (1998), The Cultural Turn: Selected Writings on the Postmodern, 1983-1998, Verso, London.

${ }^{41}$ J-F. Lyotard (1984), The Postmodern Condition, Manchester University Press, Manchester, page 5.

${ }^{42}$ F. Guattari (1995), Chaosmosis: An Ethico-Aesthetic Paradigm, Indiana University Press, Bloomington.

${ }^{43}$ See Virilio (1994).

${ }^{44}$ J. McGregor (2004), Space, Power and the Classroom, Forum 46(1): 13-23, page 30.

${ }_{45}^{45}$ E. Hooper-Greenhill (Ed.) (1999), The Educational Role of the Museum, Routledge, London.

${ }^{46}$ A. Tsorini (2009), Technology Fatigue in Digital Interactive Exhibitions. Engage, 24, 27-32

${ }^{47} \mathrm{~K}$. Schubert (2000), The Curator's Egg: The Evolution of the Museum Concept from the French Revolution to the Present Day, One-Off Press, London.

${ }^{48}$ See Bauman (2007), page 52.

${ }^{49}$ N. Prior (2003), Having One's Tate and Eating It: Transformations of the Museum in a Hypermodern Era, in A. McClellan (Ed.) Art and Its Publics: Museum Studies at the Millennium, Blackwell, Oxford.

${ }^{50}$ N. Prior (2011), Postmodern Restructurings, in S. Macdonald (Ed.), A Companion to Museum Studies, Wiley Blackwell, Chichester.

${ }^{51}$ See Prior (2003), page 64.

${ }^{52}$ Hooper-Greenhill (2000).

${ }^{53}$ S. Ashley (2005), State Authority and the Public Sphere: Ideas on the changing role of the museum as a Canadian social institution, Museum and Society 3(1): 5-17.

${ }^{54}$ J. Clifford (1997), Routes: Travels and Translation in the Late Twentieth Century, Harvard University Press, Harvard.

${ }_{55}^{5}$ M. Augé (2008), Non-Places: An Introduction to Supermodernity, Verso, London.

${ }^{56}$ L. Borzak (ed.) (1981), Field Study: A Source Book for Experiential Learning, Sage, Beverly Hills, page 34.

${ }^{57}$ E. Goffman (1959), The Presentation of Self in Everyday Life, Anchor, New York.

${ }^{58}$ D. Bohm (2007), On Dialogue, Routledge, London.

${ }^{59}$ J. Dewey (1938), Experience and Education, Collier Books, New York.

${ }^{60}$ J. Dewey (2007), Democracy and Education, The Echo Library, Teddington.

${ }^{61}$ J. Dewey (2009), Art and Experience. New York: Perigree Books.

${ }^{62}$ R. Usher, I. Bryant and R. Johnston (1997), Adult Education and the Postmodern Challenge, Routledge, London.

${ }^{63}$ C. Weedon (2004), Identity and Culture: Narratives of Difference and Belonging, Open University Press, Buckingham.

${ }^{64}$ Z. Bauman (2000), Liquid Modernity, Polity Press, Cambridge.

${ }^{65}$ See Augé (2008).

${ }^{66} \mathrm{~N}$. Addison (2008), Agency in Gallery Education, Engage 22: 13-18.

${ }^{67}$ Hooper-Greenhill (2007), page 199.

${ }^{68}$ J. Bennett (2000), Beyond Understanding: Curatorship and Access in Science Museums, in S. Lindqvist (Ed.), Museums of Modern Science, MA, Canton, History of Science Publications and the Nobel Foundation.

${ }^{69} \mathrm{~S}$. Macdonald (2004), Exhibitions and the Public Understanding of Science Paradox, Pantaneto, 13.

${ }^{70}$ C. Bruce (2006), Experience Music Project as a Post-museum, in J. Marstine (Ed.), New Museum Theory and Practice, Blackwell Oxford.

${ }^{71}$ S. Papert (1980), Mindstorms: Children, Computers and Powerful Ideas, Basic Books, New York.

${ }^{72}$ Hooper-Greenhill (2000), page 152.

${ }^{73}$ A. Irwin and B. Wynne (eds.) (1996), Misunderstanding Science: the Public Reconstruction of Science and Technology, Cambridge University Press, Cambridge.

${ }^{74}$ J. Wilsdon and R. Willis (2004), See-Through Science: Why Public Engagement Needs to Move Upstream, Demos, London.

${ }^{75}$ S. Jasanoff (2005), Designs on Nature: Science and Democracy in Europe and the United States, Princeton University Press, Princeton NJ.

${ }^{76}$ N. Serota (2000), Experience or Interpretation. The Dilemma of Museums of Modern Art, Thames \& Hudson, London, page 35

${ }^{77}$ R. Lachapelle, D. Murray and S. Neim (2003), Aesthetic Understanding as Informed Experience, Journal of Aesthetic Education 37(3): 87

${ }^{78}$ A. Craft (2005), Creativity in Schools: Tensions and Dilemmas, Routledge, London.

${ }^{79}$ M. Greene (1995), Releasing the Imagination: Essay; on Education, the Arts, and Social Change, Jossey-Bass Publishers, CA.

${ }^{80}$ M. Csikszentmihalyi (1998), Finding Flow: The Psychology of Engagement With Everyday Life, Basic Books, New York.

${ }^{81}$ E.W. Eisner (1994), The Educational Imagination: On the Design and Evaluation of School Programs, Macmillan, New York.

${ }_{83}^{82}$ E.W. Eisner (2002), The Arts and the Creation of Mind, Yale University, New Haven.

${ }^{83}$ R. F. Mitchell (2009), Current Trends in Classroom Research, in M.H. Long and C.J. Doughty (Eds.), The Handbook of Language Teaching, Wiley-Blackwell, Oxford. 
${ }^{84}$ S. Ashley (2005), State Authority and the Public Sphere: Ideas on the changing role of the museum as a Canadian social institution, Museum and Society 3(1): 5-17

${ }^{85}$ P. Bourdieu and A. Darbel (1991), The Love of Art: European Art Museums and Their Public, Stanford University Press, Palo Alto, CA

${ }^{86}$ Z. Bauman (1988), Intimations of Postmodernity, Polity Press, Cambridge.

${ }^{87}$ J. Habermas (1989), The Structural Transformation of the Public Sphere, Polity, Cambridge.

${ }^{88}$ Hooper-Greenhill (2000), page 153.

${ }^{89}$ C. Taylor (2002), Modern Social Imaginaries, Public Culture 14(1): 91-124.

${ }^{90} \mathrm{G}$. Claxton (1999), Wise Up: The Challenge of Lifelong Learning, Bloomsbury, London.

${ }_{91}^{91}$ N. Addison (2008), Agency in Gallery Education, Engage 22: 13-18

92 J. Durant (1999), Participatory Technology Assessment and the Democratic Model of the Public Understanding of Science, Science and Public Policy 26: 313-319.

${ }^{93}$ C. Marris, B. Wynne, P. Simmons and S. Weldon (2001), Public attitudes to agricultural biotechnologies in Europe: Final report of PABE research project, Centre for the Study of Environmental Change (CSEC), Lancaster University, Lancaster, U.K., http://csec.lancs.ac.uk/pabe/docs/pabe_finalreport.pdf.

${ }^{94}$ V. Turner (1985), Liminality, Kabbalah, and the Media, Academic Press, London.

${ }_{95}$ G. Bazin (1967), The Museum Age, Universe Books, New York, page 65

${ }^{96}$ Hooper-Greenhill (2000).

${ }_{97}^{97}$ S. Pearce (Ed.) (1995), Art in Museums, Athlone Press, London.

${ }^{98}$ E. Hooper-Greenhill (1994), Museums and their Visitors, Routledge, London, page 169.

${ }^{99}$ S. Weil (2002), The Museum and the Public. Making Museums Matter, Smithsonian Institution Press, Washington, page 201.

${ }^{100}$ C. Doherty (2004), The Institutions is Dead! Long Live the Institution! Contemporary Art and New Institutionalism, Engage 15: 6-13.

${ }^{101}$ M. Kalliala (2006), Play Culture in a Changing World, Open University Press, Berkshire, England.

\section{Author}

Dr Richard Watermeyer is a Research Fellow at the ESRC Centre for Economic and Social Aspects of Genomics at Cardiff University. His work is at the intersection of Science Technology Studies (STS) and the Sociology of Education with specific interests in innovative pedagogies, object-based and experiential forms of learning; creative processes in the visualization of scientific complexity; the governance of science; spaces/methods of upstream dialogue and co-constructions of expert knowledge. E-mail: WatermeyerRP@cardiff.ac.uk.

How TO CITE: $\quad$ R. Watermeyer, A conceptualisation of the post-museum as pedagogical space, Jcom 11(01) (2012) A02. 